\title{
Public health, universal health coverage, and Sustainable Development Goals: can they coexist?
}

\author{
Harald Schmidt \\ University of Pennsylvania \\ Lawrence O. Gostin \\ Georgetown University Law Center, gostin@law.georgetown.edu \\ Ezekiel Emanuel \\ University of Pennsylvania
}

This paper can be downloaded free of charge from:

https://scholarship.law.georgetown.edu/facpub/1491

http://ssrn.com/abstract=2625208

Harald Schmidt, Lawrence O. Gostin \& Ezekiel J. Emanuel, Public health, universal health coverage, and Sustainable Development Goals: can they coexist?, The Lancet, published Online First (June 30, 2015)

This open-access article is brought to you by the Georgetown Law Library. Posted with permission of the author. Follow this and additional works at: https://scholarship.law.georgetown.edu/facpub

Part of the Health Law and Policy Commons, Health Policy Commons, International Public Health Commons, Public Health Education and Promotion Commons, and the Public Policy Commons 


\title{
Public health, universal health coverage, and Sustainable Development Goals: can they coexist?
}

\author{
Harald Schmidt, Lawrence O Gostin, Ezekiel J Emanuel
}

In her 2012 reconfirmation speech as WHO DirectorGeneral, Dr Margaret Chan asserted: “universal coverage is the single most powerful concept that public health has to offer. It is our ticket to greater efficiency and better quality. It is our saviour from the crushing weight of chronic noncommunicable diseases that now engulf the globe". ${ }^{1}$ The UN General Assembly is currently considering proposals for Sustainable Development Goals (SDGs), succeeding the Millennium Development Goals. ${ }^{2}$ SDG 3, focusing on health, specifically includes universal health coverage (UHC) among its targets.

Unquestionably, UHC is timely and fundamentally important. ${ }^{3-5}$ However, its promotion also entails substantial risks. A narrow focus on UHC could emphasise expansion of access to health-care services over equitable improvement of health outcomes through action across all relevant sectors - especially public health interventions, needed to effectively address non-communicable diseases (NCDs).

WHO first endorsed UHC in its 2005 resolution on sustainable health financing, calling on states to provide "access to [necessary] promotive, preventive, curative and rehabilitative health interventions for all at an affordable cost". ${ }^{6}$ The resolution and its UHC concept firmly and narrowly centre on health insurance packages financed through pre-payment. This narrow understanding is echoed in major recent reviews of 65 empirical studies on UHC progress. ${ }^{7-9}$ The proposed SDGs also separate population-level public health measures from UHC, addressing the former as distinct targets, not under UHC. ${ }^{2}$ Yet, a broader understanding encompassing nonclinical measures can also be found in relevant WHO documents. ${ }^{4,5}$ Independent of UHC's conceptual indeterminacy, clinical health services are an essential part of UHC, ${ }^{4,5,10}$ and are likely to dominate post-2015 state health system improvements. In implementing UHC, how can we ensure continued emphasis on the full spectrum of public health interventions?

Unmediated, a narrow UHC focus risks that five distinct pressures prioritise expanded curative clinical services at the expense of individual and population-level health promotion, prevention, ${ }^{11}$ and action on social determinants of health. ${ }^{12}$ The risk is that this focus leads to more health-care services, but worse overall health outcomes, with less equitably distributed benefits.

First, unbalanced, the introduction of UHC usually increases inequity by disproportionately benefiting the wealthiest groups. ${ }^{13}$ Although there are some exceptions, UHC progress analyses from 11 countries at different levels of development suggest poorer people often lose out initially. UHC expansion generally begins with civil servants or urban formal sector workers; ${ }^{9}$ wealthier, well connected urban populations demand and receive clinical services, while poorer and rural populations do not. Some public health interventions - such as nutrition labelling, or information campaigns on behavioural NCD risks-also tend to disproportionately benefit wealthier groups, raising similar concerns. But other populationlevel measures such as clean air acts or road-safety improvements benefit the whole population from the outset, ensuring greater equity. Targeted population-level measures can balance temporary or persistent inequities arising from the introduction of UHC.

Second, the clinical sector commonly tends to emphasise specialist curative over health promotion or preventive primary care. Interventions such as dialysis, organ transplants, or new cancer therapies-frequently introduced under UHC-often have the irresistible aura of the rule of rescue, enabling the instant saving of otherwise doomed lives. But as the addition of dialysis to the public benefit package in Thailand illustrates, doing so can entail substantial budgetary opportunity costs with unclear sustainability, ${ }^{14}$ and deprioritisation of primary and secondary prevention, ${ }^{15}$ undermining benefits to far more people than typically benefit from high-cost curative care.

Third, political and societal pressures can skew budgets towards more advanced, costly clinical services at the expense of public health. Such shifts rarely take the form of pure zero-sum situations, in which one sector gains what the other loses, but are embedded in complex allocation decisions. In Thailand, the initial 2002 Universal Coverage Scheme spending formula reserved $20 \%$ of the budget for health promotion and prevention at individual and family level (personal communication, Viroj Tangcharoensathien, International Health Policy Program, Ministry of Public Health, Nonthaburi, Thailand). With the decision to cover high-cost interventions including antiretroviral therapy in 2004, dialysis and kidney transplantation in 2008, and to account for other newly covered services, inflation, and increased outpatient and inpatient service uptake, between 2001 and 2012 the per head budget was increased by 3\% per year above inflation. But with reduced prevention and health promotion unit cost, the share of the ring-fenced budget decreased from the initial $20 \%$ to $14 \%$ over the past several years (although it has recently been decided to return to previous levels). While the clinical benefit package was expanded, no new health promotion and prevention services were added in the past decade (personal communication, Viroj Tangcharoensathien).

Similarly, Colombia introduced UHC in 1993. Since then, health plan budgets increased annually by $6.4 \%$
Published Online June 30, 2015 http://dx.doi.org/10.1016/ S0140-6736(15)60244-6 Department of Medical Ethics and Health Policy (H Schmidt PhD Prof EJ Emanuel MD), and Center for Health Incentive and Behavioral Economics (H Schmidt), Perelman School of Medicine, and Wharton School (Prof EJ Emanuel), University of Pennsylvania, Philadelphia, PA, USA; and O'Neill Institute for National and Global Health Law and WHO Collaborating Center on Public Health Law and Human Rights, Georgetown University, Washington, DC, USA (Prof L O Gostin JD) Correspondence to: Dr Harald Schmidt, Department of Medical Ethics and Health Policy, Perelman School of Medicine, University of Pennsylvania, Philadelphia, PA 19104-3308, USA schmidth@mail.med.upenn.edu

For more on the Sustainable Development Goals see https:// sustainabledevelopment.un.org/ focussdgs.html 
above inflation. Public health budgets, administered at the municipal level, stayed tied to inflation (personal communication, Ramiro Guerrero, Centro PROESA, Universidad Icesi, Cali, Colombia). Secondary prevention, provided mainly through the insurance system, is supposed to be funded by a dedicated budget, separated from curative care. However, the prevention budget by itself is insufficient, and in practice health plans typically pool budgets. Demands for curative care are usually more pressing than preventive ones, and as a result preventive care receives less than it needs (personal communication, Ramiro Guerrero). The relative stagnation of Colombia's public health funds reflects the priority that curative clinical services have had, as well as political distrust in the efficiency of municipal governance, including the identification of health needs. ${ }^{16}$ Clearly articulated broad public health policy with the same political support as clinical health can help to avoid such situations, but in practice is rarely achieved.

Additionally, as the USA and other high-income countries demonstrate, clinical services attract the bulk of resources in large part because powerful constituencies on the supply side support their prioritisation. Physicians, hospitals, and other stakeholders, including patient interest groups, campaign for prioritisation of clinical services. ${ }^{11}$ But no constituencies have similar leverage in public health, and the asymptomatic public rarely-and less passionately - demand population-level or individuallevel health promotion or prevention measures.

Fourth, most low-income and even middle-income countries lack a sufficient trained health-care workforce. ${ }^{9}$ And even if employment opportunities under UHC were scaled up equally in clinical and non-clinical sectors, clinical services are more attractive: compensation is typically higher, and clinical training generally makes physicians and nurses more marketable in high-income countries, further threatening workforce retention. ${ }^{3}$

Finally, many of the targets under SDG 3 need population-level health interventions. For instance, targets for maternal and newborn mortality, communicable diseases and NCDs, alcohol, and narcotics (3.1-3.5), sexual and reproductive health (3.7), and tobacco (3a) call for broader, largely non-clinical measures, including education, improved sanitation, hygiene, nutrition, bednets, taxation, and restrictions or bans on selling and promoting alcohol, narcotics, and tobacco. Similarly, targets for road traffic (3.6) and air, water, soil pollution (3.9) fall entirely outside clinical services.

The SDG proposal identifies UHC as a distinct target. But UHC is a means, not an end in itself. The ultimate goal must be improvement of health. Unfortunately, most population-level health targets do not include policy vehicles that can help to accomplish them.

Tobacco provides a case example. Lung cancer is among the most devastating NCDs. Globally, deaths from smoking are expected to increase greatly in low-income countries. In the 20th century, tobacco use killed around
100 million people worldwide; ten times more- 1 billionwill die in the 21st century. By 2030, low-income countries are estimated to bear more than $80 \%$ of tobacco-attributable deaths. ${ }^{17}$ Under UHC's focus on clinical services, responses generally centre on nicotine-replacement therapy, smoking-cessation programmes, surgery, radiation, and chemotherapy for lung cancer. Clinicians are likely to screen for and treat cancer, but not prevent it.

Although it is important to help ill people to regain health, it is clearly more ethical and efficient to keep them healthy in the first place. The preferred response is therefore to stringently implement the Framework Convention on Tobacco Control ${ }^{18}$-as identified under target $3 \mathrm{a}$, the only policy vehicle to achieve a non-clinical public health goal-and WHO's MPOWER strategy, which chiefly includes protections from tobacco smoke; health risk warnings; enforcements of advertising, promotion, and sponsorship bans; and raising taxes. Particularly costeffective measures such as taxation would furthermore generate revenue to fund both population-level and individual-level public health interventions. ${ }^{18}$ These measures are entirely outside the clinical-service realm and should not be sacrificed to increase budgets for detection and treatment of tobacco-related cancers under UHC.

Looking ahead, policy makers must make complex prioritisations in moving towards UHC. This process includes striking the right balance between individuallevel curative services, and individual-level and populationlevel health promotion and preventive measures. Three steps can help to ensure that increased attention to clinical services will not undermine, but support, robust action across the full range of public health measures and social determinants of health. ${ }^{12}$

First, effective cross-departmental action is needed. The risk of UHC unduly skewing the agenda becomes higher if health departments are the central focus for implementation of UHC. Optimally, states should take stock of the broader context of government action on health, including food, housing, educational, environmental, and tax policies. Effective communication and concerted action among health, finance, enterprise, and other departments is therefore imperative. ${ }^{11,12,19}$ Relaunching and structuring of health departments as departments of public health can be one way of avoiding an unduly narrow focus. The Health in All Polices (HiAP) strategyendorsed by WHO in 2009-can provide a helpful structural vehicle. Among other things, HiAP requires public health staff presence on relevant committees of other departments, health impact assessments for nonhealth policies, and joint cross-departmental health targets and evaluations. ${ }^{20}$ Progress with implementation of intersectoral strategies ${ }^{11,19}$ has been disappointingly slow. Addition of HiAP as a SDG target would complement other approaches, further focusing attention.

Second, fixed and distinct budgets are important. As noted, political and societal pressures favouring curative services under UHC can harm health promotion and 
prevention. Fixed and distinct budgets are the most appropriate way to avoid cannibalism and ensure sustainability and peaceful coexistence. Fixed budgets also focus attention on determining value for money. Thailand's approach of ring-fencing $20 \%$ of the UHC budget for health promotion and prevention is a useful model. Budgets should be sensitive to a country's level of development and be driven by epidemiological, economic, and ethical analyses, prioritising the most cost-effective and equitable measures - even if this means deprioritising curative services. In principle, the same approach would be desirable for population-level public health measures. But given that these frequently fragmented measures ${ }^{11}$ span many government departments and civil society sectors, a careful accounting of public health measures will also be necessary. This process again emphasises the importance of an approach such as HiAP, and robust analyses of alignments of efforts within a broad public health strategy.

Third, a robust public health workforce should be ensured. SDG's target 3c seeks to “increase substantially... recruitment, development, training and retention of the health workforce". As with UHC, there are risks and opportunities. Specifically, capacity building must not narrowly centre on the clinical context, should promote the public health workforce development, and be implemented in ways that reduce brain-drain likelihood. Promising strategies include locally relevant training with a focus on endemic conditions, and practising of medicine within country-specific resource scarcity constraints. This approach promotes professional prestige of local practice, equips workers with realistic expectations, and reduces chances that clinical medicine training is chosen predominantly as a stepping stone to work in high-income countries. ${ }^{21}$ Externally sponsored training should generally take the form of so-called sandwich training, with most time spent in the sponsored-not the sponsors'-country. ${ }^{22}$

The global move towards UHC by ensuring affordable access to essential health benefits is urgent and long overdue. The current enthusiasm and momentum is encouraging. However, the ultimate challenge for policy makers is not merely to improve clinical services, but to achieve equitable health outcome improvements through genuine integration of individual and population-level health promotion and preventative efforts with curative services. Future UHC evaluations should include assessments of the extent to which this integration is accomplished $^{11}$ - with particular attention to the distribution of benefits across groups-and not, as major current work, ${ }^{7-9}$ be limited to the clinical side.

\section{Contributors}

HS has conceived of and wrote the first draft of the manuscript. LOC and EJE reviewed and revised subsequent versions and discussed all substantive points in person or by email.

Declaration of interests

We declare no competing interests.

\section{Acknowledgments}

We thank Anne Barnhill, Daniel Cotlear, Leonardo Cubillos-Turriago, Eric A Friedman, Ramiro Guerrero, Felicia Marie Knaul Windish, Joe Kutzin, Trygve Ottersen, Govind Persad, Jennifer Prah Ruger, Viroj Tangcharoensathien, Suwit Wibulpolprasert, and Petronella Vergeer for comments on earlier versions of the manuscript and crucial help with specific factual queries. We are also grateful for helpful comments from the three anonymous reviewers that enabled us to clarify several central points. All errors are the authors' alone.

\section{References}

1 Chan $\mathrm{M}$. Universal coverage is the ultimate expression of fairness. Acceptance speech at the 65th World Health Assembly; Geneva, Switzerland; May 23, 2012. http://www.who.int/dg/speeches/2012/ wha_20120523/en/index.html (accessed May 29, 2015).

2 Open Working Group of the General Assembly. Open Working Group Proposal for Sustainable Development Goals. 2014. A/68/970. http://undocs.org/A/68/970 (accessed May 29, 2015).

3 Frenk J, de Ferranti D. Universal health coverage: good health, good economics. Lancet 2012; 380: 862-64.

4 WHO, World Bank. Monitoring progress towards universal health coverage at country and global levels. Geneva: World Health Organization, 2013.

5 WHO Consultative Group on Equity and Universal Health Coverage. Making fair choices on the path to universal health coverage. Geneva: World Health Organization, 2014.

6 WHO. World Health Assembly Resolution: sustainable health financing, universal coverage and social health insurance. 58th World Health Assembly; Geneva, Switzerland; May 16-25, 2005.

7 Giedion U, Alfonso EA, Díaz Y. The impact of universal coverage schemes in the developing world: a review of the existing evidence. Washington, DC: World Bank, 2013.

8 Boerma T, Eozenou P, Evans D, Evans T, Kieny M-P, Wagstaff A. Monitoring progress towards universal health coverage at country and global levels. PLoS Med 2014; 11: e1001731.

9 Maeda A, Araujo E, Cashin C, Harris J, Ikegami N, Reich MR. Universal health coverage for inclusive and sustainable development: a synthesis of 11 country case studies. Washington, DC: World Bank, 2014.

10 O'Connell T, Rasanathan K, Chopra M. What does universal health coverage mean? Lancet 2014; 383: 277-79.

11 Duran A, Kutzin J. Financing of public health services and programmes: time to look into the black box. In: Kutzin J, Cashin C, Jakab M, eds. Implementing health financing reform. Copenhagen: WHO Regional Office for Europe, 2010: 247-68.

12 Marmot M. Universal health coverage and social determinants of health. Lancet 2013; 382: 1227-28.

13 Gwatkin DR, Ergo A. Universal health coverage: friend or foe of health equity? Lancet 2011; 377: 2160-61.

14 Tantivess S, Werayingyong P, Chuengsaman P, Teerawattananon Y Universal coverage of renal dialysis in Thailand: promise, progress, and prospects. BMJ 2013; 346: f462.

15 Tangcharoensathien V, Pitayarangsarit S, Patcharanarumol W, et al. Promoting universal financial protection: how the Thai universal coverage scheme was designed to ensure equity. Health Res Policy Syst 2013; 11: 25.

16 Guerrero R, Prada SI, Chenichovsky D. La doble descentralización en el sector salud: evaluación y alternativas de política pública. Bogota: Fedesarrollo, 2014.

17 WHO. WHO report on the global tobacco epidemic, 2008 - the MPOWER package. Geneva: World Health Organization, 2012.

18 Jamison DT, Summers LH, Alleyne G, et al. Global health 2035: a world converging within a generation. Lancet 2013; 382: 1898-955.

19 Exworthy M. Policy to tackle the social determinants of health: using conceptual models to understand the policy process. Health Policy Plan 2008; 23: 318-27.

20 Kickbusch I. Healthy societies: addressing 21st century health challenges. Adelaide: Adelaide Thinkers in Residence, Government of South Australia, 2008.

21 Eyal, Nir, and Samia A. Hurst. Physician brain drain: can nothing be done? Public Health Ethics 2008; 1: 180-92.

22 Lazarus JV, Wallace SA, Liljestrand J. Improving African health research capacity. Scand J Public Health 2010; 38: 670-71. 